\title{
A CLASSIFICAÇÃO NOS DOMÍNIOS DAS TRÊS MARIAS
}

\section{LA CLASIFICACIÓN EN EL DOMINIO DE LAS “TRES MARÍAS”}

\author{
Jéssica Camara Siqueira - jessica.camara@yahoo.com.br \\ Mestranda em Ciência da Informação na ECA-USP \\ Bolsista CAPES
}

\begin{abstract}
Resumo
O artigo destaca que a análise terminológica do termo "classificação", na Arquivologia, Biblioteconomia e Museologia revela similitudes e distinções entre os domínios. Observa as relações entre as "três Marias" a partir de um corpus multilíngue, com predominância de publicações dos últimos 25 anos, com textos de natureza primária e secundária, a partir das fichas de análise e síntese, conforme sugere Smit (1993). Destaca as propostas de definições mostrando que o termo "classificação" possui duas acepções: uma de natureza físico-material e outra cognitiva, com destaque para a última, responsável pela estruturação sistemática e a elaboração de classes. Enfatiza que a separação dos documentos por atributos comuns marca também a distinção entre os domínios, que utilizam critérios singulares para o estabelecimento de classes. Finaliza com a constatação que mesmo considerando as especificidades de cada domínio, há uma nítida contiguidade entre as "três Marias", o que revela uma necessidade cada vez mais evidente de diálogo e trocas para o estabelecimento de um campo de estudo mais articulado e voltado às necessidades do contexto contemporâneo.
\end{abstract}

\section{Palavras-chave}

Arquivologia - classificação. Biblioteconomia - classificação. Museologia - classificação. Classificação. Terminologia.

\section{INTRODUÇÃO}

A necessidade de sistematizar o conhecimento é antiga, já que remonta à tentativa humana de representar e ordenar o mundo externo. Tal tarefa não é fácil, já que a categorização dos processos de conhecimento leva em conta parâmetros histórico-sociais, o que dificulta uma delimitação espaço-temporal, não permitindo, portanto ter um caráter permanente.

Esse caráter efêmero da classificação ocorre pelo fato de, ao sistematizar o conhecimento em classes, o próprio objeto de estudo se modifica, por conta das relações que ele estabelece com outros objetos analisados. Nesse viés, Foucault 
(1996), retoma o texto de Borges, sobre uma enciclopédia chinesa, ratificando a arbitrariedade da classificação:

[...] O texto de Borges aponta para outra direção; a essa distorção da classificação [...] Quando instauramos uma classificação refletida, quando dizemos que um gato e o cão se parecem menos que dois galgos, mesmo se ambos estão adestrados ou embalsamados, mesmo se correm como loucos e mesmo se acabam de quebrar a bilha, qual é, pois, o solo a partir do qual podemos estabelecê-lo com inteira certeza? [...] Que coerência é essa- que se vê logo não ser determinada por um encadeamento a priori e necessário, nem imposta por conteúdos imediatamente sensíveis? Pois não se trata de ligar consequências, mas sim de aproximar e isolar, de analisar, ajustar e encaixar conteúdos concretos, nada mais tateante, nada mais empírico[...]. (FOUCAULT, 1996, p.8-9)

No decorrer da obra As palavras e as coisas, Foucault (1996) retoma tal ideia, em seu capítulo sobre a Classificação, esmiuçando algumas de suas bases, como a estrutura, o método e o sistema. Para ele, o sistema é o conjunto limitado de aspectos que se constituem a partir de uma estrutura, lugar onde as identidades e variações serão observadas, verificando-se sua eficiência combinatória. Já o método, ao contrário do sistema, descreve progressiva e exaustivamente um elemento para depois estabelecer analogias.

Outra contribuição importante do autor é expor que os conhecimentos são norteados pelo conceito da semelhança, ou seja, as classificações se constituem a partir de similaridades, e relações de subordinação entre seres que compõem a realidade. Assim, até meados do século XVII as classificações se organizavam segundo tais princípios, numa perspectiva em que a natureza era vista como um todo articulado, que se relacionava com os seres e as coisas ao redor, a partir da analogia. Nessa tentativa de traduzir o mundo a partir da observação, em que o "visível" opera a partir de variáveis (forma, quantidade, grandeza relativa e distribuição dos elementos no espaço), percebeu-se que os objetos eram agrupados não somente por semelhança, mas também a partir de uma ordem e distintos graus de diferenciação.

Outra vertente de estudo, influenciada por um determinismo intrínseco nas próprias estruturas classificatórias, está nos trabalhos de Durkheim e Mauss (1981), como por exemplo, na obra De quelques formes primitives de classification. Os autores balizam que a organização de uma classe está mais associada à observação direta do mundo real, ao invés de uma elaboração abstrata, o que resulta numa classificação moldada segundo as categorias sociais, reflexos das relações familiares, socioeconômicas, políticas e culturais.

Mauss ao estudar a organização de povos primitivos notou um estreito vínculo entre os sistemas sociais e seus respectivos sistemas lógicos, o que lhe permitiu se aprofundar nos estudos sobre as categorias do pensamento $e$ concluir, a partir de uma argumentação sociológica, que a categorização é um produto da representação coletiva. Para ele "aquilo que categoriza é a sociedade e a história [...] as categorias vivem e morrem com os povos e seus diversos contributos" (MAUSS, 2001 apud ARTÊNCIO, 2007, p.51). 
A classificação para Mauss tinha a função de ordenar os seres e acontecimentos, em gêneros e espécies, relacionando-os a partir de inclusões, exclusões e subordinações. Para isso, associava ideias e estabelecia contiguidades com o intuito de explicar as relações entre os conceitos, que observados em suas transformações histórico-sociais, desvelavam a passagem de uma categoria para outra, ratificando sua visão sobre representações coletivas.

Seguindo essa perspectiva sociocêntrica da classificação, temos outros autores, como Lévi-Strauss, que afirma que, diferente da visão ocidental, a classificação instituída pelos homens primitivos não era hierárquica, mas tinha uma estrutura vertical que conectava o geral com o específico, e o abstrato com o concreto. Dessa forma, o autor salienta o aspecto da inviabilidade e artificialidade dos sistemas classificatórios, atados pela organização hierárquica e representados por classes finitas, dizendo: "Las clasificaciones filtran y aprisionan lo real” (LÉVI-STRAUSS, 1964 apud SAN SEGUNDO, 1996, p.30).

Para Piaget (1979), a classificação não é só algo da natureza humana, como uma "ficção útil", pois nossa mente precisa de modelos pré-fabricados da realidade a fim de estabelecer analogias, e com isso compreender melhor a si mesmo e o mundo que nos cerca. Observando o cérebro de crianças, Piaget (1979) constatou que toda classificação parte de uma abstração, que de forma simplificadora e arbitrária, está implícita em toda operação mental, e atua tanto no âmbito da linguagem como na lógica para se estabelecerem os sentidos das coisas (GROLIER, 1982). Já para Grolier (1982), a classificação é um "artefato cultural", já que resulta não só dos aspectos culturais, como das condições políticas, sociais, econômicas e de suas inter-relações.

Observando tal multiplicidade de caminhos, Diemer (1974, apud SAN SEGUNDO, 1996), aponta quatro grandes orientações classificatórias: a ontológica, ligada à classificação dos seres; a gnosiológica, voltada à Ciência; e as classificações biblioteconômica e informacional, voltadas à determinação de seus meios de realização.

Perelman (1963), também tentando entender tal universo, assinalou duas visões básicas para a classificação: a perspectiva dicotômica, baseada na presença ou ausência de uma determinada propriedade, e as classificações que se constituem a partir de uma propriedade caracterizada com diferença específica. Como exemplo da primeira, temos a clássica Árvore de Porfírio, baseada na teoria dos predicados de Aristóteles, que representa um conjunto hierárquico finito de gêneros e espécies, marcados por dicotomias sucessivas; já no outro caso, temos como exemplo a classificação das ciências, em que observamos várias propriedades que podem originar distintas classificações (ARTÊNCIO, 2007).

A partir do breve elencar de perspectivas sobre classificação, percebemos que não há um modelo único, pois os critérios variam conforme perspectivas e valores assumidos, assim parece mais viável considerar a importância de tal processo para a natureza humana, mesmo diante de seu caráter arbitrário. Pombo (1998), em seu artigo Da classificação dos seres à classificação dos saberes, retoma as reflexões de Foucault (1996) sobre classificação, ratificando 
sua relevância para nossa representação de realidade, marcada pela naturalidade e arbitrariedade:

$\mathrm{Na}$ verdade, nada nos parece mais "natural", óbvio e indiscutível que as classificações dos entes, dos factos e dos acontecimentos que constituem os quadros mentais em que estamos inseridos. Elas constituem os pontos estáveis que nos impedem de rodopiar sem solo, perdidos no inconforto do inominável, da ausência de "idades" ou "geografias". Só elas nos permitem orientar-nos no mundo à nossa volta, estabelecer hábitos, semelhanças e diferenças, reconhecer os lugares, os espaços, os seres, os acontecimentos; ordená-los, agrupá-los, aproximá-los uns dos outros, mantê-los em conjunto ou afastá-los irremediavelmente. (POMBO, 1998, p.19).

Podemos auferir assim, que a tentativa humana de estabelecer classes ou categorias mais do que uma ação supostamente de controle, é uma das formas mais hábeis de se representar uma realidade, trazendo subjacente o intuito de transformá-la em conhecimento. Assim, ao utilizarmos tal "estratégia" de representação de mundo estamos estabelecendo analogias e identidades que constituirão um sistema de conceitos (SIQUEIRA, 2009).

É notório que tais sistemas trarão em seu bojo traços culturais, sociais, ideológicos e institucionais, fruto da perspectiva daquele que lhe delineou. Com o intuito de compreender tais particularidades conceituais serão discutidas as principais noções de classificação nos domínios da Arquivologia, Biblioteconomia/Documentação e Museologia.Com o objetivo de verificar as similitudes e as distinções do termo classificação nesses domínios, utiliza-se a abordagem terminológica, para coleta, análise e síntese das definições. Para tanto, a metodologia empregada segue os preceitos terminográficos de Cabré (1993), Barros (2004) e Lara (2005).

O estabelecimento do corpus de trabalho, por exemplo, dividiu-se em dois momentos, a seleção do corpus de referência, constituído de obras que serviram de apoio para compreensão do domínio e a escolha do corpus de análise, que correspondeu aos textos em que foram analisadas as unidades terminológicas. Para a análise foram considerados critérios qualitativos e quantitativos. No âmbito qualitativo, consideraram-se os seguintes critérios: a natureza, primária ou secundária das fontes; o idioma (português, francês, espanhol e inglês); e cronológico (publicações dos últimos 25 anos). No âmbito quantitativo, elegeramse oito definições do termo classificação para cada domínio, elencando para cada uma, quatro características de análise, que por fim constituíram as fichas de síntese e a definição do termo em cada domínio. Tal procedimento foi ilustrado com árvores de domínio para cada uma das "irmãs", o que corroborou a observação das inter-relações e distinções entre as Três Marias.

\section{A CLASSIFICAÇÃO E AS "TRÊS MARIAS"}


A denominação "Três Marias" foi cunhada por Smit (1993), ao propor uma simplificação das relações entre Arquivologia Biblioteconomia/Documentação e Museologia, para fins didáticos. A expressão "Três Marias" procura demarcar a proximidade das áreas, evidenciando que mesmo em espaços diferentes e com suas particularidades, "coletam, processam, e disseminam conteúdos informativos" (SMIT, 2000), já que têm como objetivo comum a organização da informação. Homulos (1990) até aproxima mais esse "parentesco", dizendo que é difícil distinguir, no contínuo das três profissões, onde termina a função de uma e começa a de outra. Assim, confirma uma tendência cada vez mais evidente de diálogo entre elas.

Todavia, apesar do contexto de contiguidade, e do compartilhamento de objetivos, técnicas e condições adversas, principalmente no que tangem as questões da cultura, memória e informação, não há muitas iniciativas de proximidades entre as "Três Marias". Há uma preponderância de uma postura isolacionista, sedimentada pelas práticas profissionais, restringindo possíveis trocas de informação, obliterando uma visão mais abrangente das áreas em questão.

Remontando às origens, da Antiguidade à Idade Média, com as primeiras bibliotecas, notamos o acúmulo de materiais tanto bibliográficos como de natureza arquivística, cuja separação em termos de embrião de domínios se tornou mais clara só após a invenção da imprensa, que com a duplicação de textos acabou separando os espaços da biblioteca e do arquivo. Já o museu, como o conhecemos atualmente, surge no século XVIII, como fruto dos gabinetes de curiosidades da época das Grandes Navegações.

Um primeiro fator de aproximação, além da origem comum, é o trabalho com o documento, pois ele acaba agregando práticas profissionais comuns. Mesmo na Museologia, que para muitos o documento não é visto no sentido imediato do termo, há uma ênfase contemporânea em enxergá-lo como informação. Otlet (1996) já ampliava o conceito de documento ao dizer que era o "registro do pensamento humano e da realidade exterior em elementos de natureza material", entendendo-o como uma unidade intelectual e abstrata, que poderia revestir-se de outras modalidades e até ser comparada a outras unidades essenciais das Ciências, como a célula e o átomo.

Essa perspectiva de ampliar o conceito de documento, notada em Otlet (1996), era um prenúncio da preocupação em promover o diálogo entre os trabalhos de arquivistas, bibliotecários e museólogos, às entidades internacionais, como a Organização das Nações Unidas para a Educação, a Ciência e a Cultura (UNESCO) e a Federação Internacional das Associações e Instituições Bibliotecárias (IFLA) que através de congressos, simpósios e compatibilização de currículos dos cursos de formação, tiveram o intuito de convergir saberes e funções comuns entre as três irmãs, a fim de diminuir seu isolacionismo, promovendo maior cooperação entre as áreas.

Tal aproximação seria positiva tanto para constatar os elementos que unem a Arquivologia, Biblioteconomia e Museologia, como para estabelecer suas distinções. Mesmo com elemento-chave comum, a informação institucionalizada, 
há diferenças quanto à gestão da memória, produção e mediação da informação, portanto, devemos levar em conta o campo de conhecimento, a metodologia e a terminologia das "Três Marias".

Com o intuito de compreender proximidades e distinções entre as três Marias elegemos o termo "classificação" a fim de pontuar as inter-relações através da análise terminológica. A escolha do termo levou em consideração três critérios: ser um termo comum nos três domínios, ter relevância para as principais operações desempenhadas em cada uma das três irmãs e possuir um cabedal bibliográfico que pudesse ser usado no estudo terminológico.

Quanto ao termo classificação, observa-se que ele se faz presente nos três domínios há tempos remotos. Desde as primeiras organizações funcionais de documentos com as civilizações pré-clássicas, no arquivo, na biblioteca e no museu, como se verifica, por exemplo, no colecionismo de objetos sagrados em templos. Nesse período já acontecia de forma rudimentar, uma preocupação em coletar e armazenar as informações dos povos conquistados, o que também exigia uma classificação.

Atualmente, no contexto de explosão informacional, automatização dos processos documentais e valorização do sujeito no processo de recuperação informacional, fica evidente a relevância do termo classificação no âmbito das três Marias. Considerado tanto numa perspectiva física como intelectual, tal termo reporta à almejada organização e estruturação informacional, que num momento de descontinuidades e fragmentações tem o importante papel de tentar estabelecer algum tipo de consolidação dos domínios.

\subsection{O termo classificação no domínio da Biblioteconomia}

Pérez-Pulido, em sua obra Teoría y nuevos escenarios de la biblioteconomia (2005), além de traçar um panorama histórico da disciplina, procura entender as mudanças sofridas pelo conceito no contexto pós-moderno com a aplicação de novas tecnologias de informação e comunicação. Depois de longa análise propõe a seguinte definição para Biblioteconomia:

\footnotetext{
Parte integrante de las ciencias de la documentación que se ocupa de la biblioteca como sistema de información, y tiene por objeto hacer cumplir su función social mediadora a fin de responder satisfactoriamente a la demanda de los usuarios en una sociedad en continuo cambio (PÉREZ-PULIDO, 2005, p.53).
}

Ainda não se chegou a um consenso: dependendo da vertente, a Biblioteconomia pode ser vista como ciência, disciplina ou técnica. A aplicação das novas tecnologias de informação e comunicação, bem como o contexto contemporâneo interdisciplinar, também não contribuem para formular respostas definitivas, já que trazem em seu cabedal outras arestas para área, como a inesgotável discussão acerca do documento, que agora ganha outra nova faceta, a digital.

Quanto à análise do termo classificação no domínio da Biblioteconomia, podemos observar que se reporta a dois aspectos principais: um de natureza 
intelectual e outro material, bem demarcados por Jouguelet (1997). No caso da operação intelectual temos dois traços principais, a organização temática e a organização de um sistema de classificação, enquanto na operação material o traço relevante é a ordenação física. Aparece ainda outra característica, que se relaciona tanto com a ordem física quanto à intelectual, que são os produtos da classificação: catálogos, índices e bibliografias sistemáticas.

Analisando a classificação como uma operação intelectual, notamos que a organização temática e o sistema de classificação estabelecem entre si uma relação associativa, já que a primeira, voltada à determinação do assunto de um documento, recorre ao sistema de representação sistemática para agrupar os registros com características comuns (classes). O sistema de classificação, por sua vez, volta-se ao estabelecimento de classes cuja estruturação recorre à identificação de semelhanças e diferenças, bem como a distinções temáticas.

A ordenação física, mesmo estando num nível operacional distinto, também se relaciona com o nível anterior, já que a localização relativa de um documento em uma coleção reflete seu sistema de classificação. Logo, há uma relação associativa entre tais elementos. Além disso, ainda servirão de base para a origem de outro atributo encontrado nas fichas de análise, os produtos da classificação, voltados ao acesso e recuperação informacional: os índices, catálogos e bibliografias sistemáticas, subordinados aos atributos da ordenação física e ao sistema de classificação.

Considerando as definições e a representação gráfica analisada, propõemse a seguinte definição para o termo classificação, no domínio da Biblioteconomia, na ficha de síntese:

É um conjunto de operações de natureza intelectual ou física efetuadas para ordenar uma coleção, de acordo com um esquema racional pré-determinado. Na perspectiva intelectual, agrupam-se metodicamente as ideias a partir de suas semelhanças e diferenças, organizando os elementos em classes que representam um determinado assunto ou nível de conhecimento. No âmbito material, provê a possibilidade de organização de documentos num determinado espaço visando sua localização e acesso, utilizando para isto instrumentos de recuperação, como índices, catálogos e bibliografias sistemáticas (SIQUEIRA, 2009, p.57).

\subsection{O termo classificação no domínio da Museologia}

O museu, assim como a biblioteca é um órgão colecionador, que reúne artificialmente materiais e os classifica segundo sua natureza e finalidade específica. Assim, segundo Otlet (1996), ambos têm em comum o objetivo e a finalidade, mesmo que se diferenciem principalmente quanto à natureza do acervo - predominância de objetos bi/tridimensionais na primeira e de livros e periódicos na segunda. Diferente do arquivo, que tem como objetivo primário fins administrativos e jurídicos, o museu e a biblioteca estão voltados para fins educativos, culturais e científicos. 
Outro aspecto que é importante ressaltar é a diferença entre museologia e museografia, termos muitas vezes tomados como sinônimos, mas que são de naturezas distintas. A Museologia é uma ciência que estuda a relação específica do homem com a realidade, e consiste na coleta e conservação sistemática e seletiva de objetos que documentam o desenvolvimento da natureza e da sociedade. Já a museografia diz respeito à prática da museologia, ou seja, as técnicas, os métodos de trabalho e as habilidades desenvolvidas no museu (CERÁVOLO, 2004).

O termo classificação no âmbito da Museologia, diferente das outras duas acepções anteriores, exigiu uma pesquisa mais apurada, já que a bibliografia nacional é escassa e em grande parte reúne trabalhos de caráter prático. Diante desse contexto, foi necessário considerar para esta análise definições em outros idiomas. Além disso, por conta da escassez de fontes de referência foi necessário fazer uma delimitação temporal mais extensa, considerando materiais de 1951 a 1999.

Assim como na Biblioteconomia, na Museologia, o termo classificação pode ser definido basicamente por dois aspectos: um de natureza física, denominado ordenação, e outro de caráter cognitivo, a categorização. Ambas as designações parecem muito próximas nas fichas terminográficas, sendo até consideradas como sinônimas por Bianchinia e Ferrez (1987), muito embora notemos que se diferenciem quanto à função que desempenham. Enquanto a ordenação está voltada para uma organização física do acervo, a categorização, numa ação mais elaborada, estabelece classes que irão compor as diversas facetas da coleção, que por sua vez considerando outros aspectos para sua composição.

Para o estabelecimento de categorias são levados em conta basicamente três fatores: a natureza da coleção, a perspectiva do sujeito ou da civilização de origem, e a função do objeto. Tais atributos, portanto estabelecem uma relação de subordinação com o caráter de categorização, já que serão os critérios utilizados para compor uma categoria ou classe no museu.

Quanto à natureza da coleção, por exemplo, Maroevic (1998) expõe alguns tipos de museus especializados, como os de história natural, ciência e tecnologia, etnografia e outros que reúnem objetos segundo uma temática comum. Já sobre o segundo critério, Dudley (1979) ressalta que deve ser o primeiro a ser considerado na classificação, ou seja, antes de tudo deve-se verificar a civilização humana que produziu o objeto, ou como Rocha (1999) também aponta, considerar a perspectiva do sujeito que produziu a obra. A função do objeto também é outro aspecto relevante, e que geralmente está atrelada à natureza de seu material, bem como outras informações observadas no objeto, que devem ser consideradas numa categorização.

Ao observarmos tais aspectos isoladamente poderíamos ter a errônea ideia de que funcionam separadamente, no entanto são fatores que se inter-relacionam para compor uma classificação. Se pensarmos no âmbito da categorização, por exemplo, dependendo do objeto ou coleção devemos considerar os três aspectos mencionados acima, como por exemplo, no caso de um artefato arqueológico. No entanto, se pensarmos numa obra de arte pós-moderna, o funcional generaliza-se à apreciação estética, e a questão da civilização também fica num segundo plano, 
evidenciando-se a natureza da coleção e a perspectiva do sujeito que a referencia.

Considerando as definições e a representação gráfica analisada, propõemse a seguinte definição para o termo classificação, no domínio da Museologia, na ficha de síntese:

A classificação pode ser entendida sob dois aspectos: um de natureza física e outro cognitiva. O primeiro corresponde à ordenação, que está voltada à organização física do acervo, enquanto a outra, a categorização, a partir de análise e síntese, estabelece as categorias ou classes do acervo. Tal categorização é realizada basicamente segundo três critérios: a natureza da coleção, a perspectiva do sujeito ou civilização de origem e a função do objeto (SIQUEIRA, 2009, p. 60).

\subsection{O termo classificação no domínio da Arquivologia}

Ao contrário das duas "irmãs" que também lidam com a informação registrada e até compartilham procedimentos técnicos, notamos que a informação arquivística origina-se de fontes únicas, que se organizam segundo sua proveniência para fins de prova, principalmente utilizadas em contextos jurídicos e administrativos. Dessa forma Lodolini (1988, apud FONSECA, 2007, p.39) define arquivo como: "a sedimentação documentária das atividades administrativas, cujos elementos estão ligados por um vínculo original, necessário e determinado".

É relevante também pontuar a distinção entre Arquivística e Arquivologia. De maneira sintética podemos dizer que a Arquivística seria uma disciplina voltada à gestão da informação orgânica do arquivo, enquanto que a Arquivologia seria uma ciência que estuda princípios e procedimentos metodológicos empregados no âmbito arquivístico (FONSECA, 2007). Thomanssen (1999, apud FONSECA, 2007, p. 59) por outro lado, diz que na verdade agora é que a Arquivologia está se tornando realmente ciência, pois em sua fase clássica funcionava como uma disciplina auxiliar da História e do Direito, mas que agora em sua fase pós-moderna ganhou o estatuto de ciência, deslocando seu objeto do arquivo para a informação arquivística.

A classificação neste domínio também pode ser encarada sob dois aspectos, um que está voltado à ação intelectual e outro a uma perspectiva operacional. No primeiro caso o caráter da ação intelectual guia tanto a organização sistemática, que origina o sistema de classificação, como constitui a estruturação de operações segundo a função, atividade ou assunto de determinado fundo. Já o âmbito operacional diz respeito à disposição físicomaterial, que está ligado ao Plano de Classificação.

Ambos os aspectos, intelectual e operacional, estiveram presentes nas ficha de análise.No primeiro caso as duas características estão subordinadas à ação intelectual, sendo que uma está voltada para uma estruturação de acordo com as funções e atividades da entidade produtora, e a outra se estrutura com base nas divisões e subdivisões do conjunto de documentos em grupos e subgrupos, estabelecendo entre si uma relação associativa, já que estão interligadas quanto à sua função e execução. 
Observando mais detalhadamente os dois primeiros aspectos, a ação intelectual e a disposição físico-material, notamos que são características de naturezas diferentes e que mesmo subordinadas ao termo classificação, entre si estabelecem uma relação associativa, já que apresentam proximidade espaçotemporal envolvendo uma relação de cognição-execução.

O Plano de classificação, feito com base nas funções e atividades de um sistema, é um "instrumento" de classificação que ilustra os dois níveis de atributos encontrados na análise: o intelectual e o físico-material. Mesmo sendo um quadro ou tabela criado para fins da recuperação e localização de documentos, não há como não considerar o componente intelectual na sua constituição, bem como a estruturação sistemática observando os aspectos das funções e atividades da entidade produtora para delimitá-lo. Nesse ponto é relevante ressaltar que mesmo que as características estejam separadas, para fins de análise, podem ser consideradas numa perspectiva relacional, já que entre si estão conectadas e estabelecem algum tipo de proximidade espaço-temporal.

Outro ponto importante para delimitação do termo é observar os sinônimos encontrados. Foi possível verificar que, grande parte das vezes, opta-se entre o termo Arranjo e Plano de Classificação, ou seja, privilegia-se o aspecto do "produto da classificação". Geralmente representado em forma de quadro ou tabela, o plano de classificação é baseado em critérios de estudo orgânicos, cronológicos, geográficos, temáticos ou alfabéticos que agrupam os documentos segundo as suas semelhanças ou diferenças, possibilitando a localização de uma série arquivística. Quanto à escolha "Arranjo", pode-se considerar a observação de Gonçalves (1998), para quem, no meio arquivístico brasileiro, foi consagrada a distinção entre "classificação" e "arranjo". De acordo com tal distinção, a "classificação" corresponderia às operações técnicas destinadas a organizar a documentação de caráter corrente, a partir da análise das funções e atividades do organismo produtor de arquivos. Por seu turno, o "arranjo" englobaria as operações técnicas destinadas a organizar a documentação de caráter permanente (GONÇALVES, 1998, p.2).

Assim segundo a autora, o que diferencia a classificação do arranjo é o caráter de temporalidade, ou seja, o arranjo corresponde às operações que estruturam os documentos no arquivo de guarda permanente, e a classificação destina-se à organização documental do arquivo corrente. Gonçalves (1998) ainda ressalta a importância do organismo produtor e de suas funções e atividades na constituição da classificação, evidenciando assim sua dimensão intelectual.

Considerando as definições e as representações gráficas analisadas, propõem-se a seguinte definição na ficha de síntese para o termo classificação, no domínio da Arquivologia:

A classificação é uma operação que recorre à estruturação lógicosemântica para ordenar os elementos de um conjunto de acordo com as suas semelhanças e diferenças, agrupando-os em classes, grupos e subgrupos, e considerando para tal ação as funções e as atividades do organismo produtor do arquivo. Também pode ser considerada como uma disposição físicomaterial, voltada à organização física do arquivo e tendo como 
produto o Plano de Classificação. Além da denominação classificação, mais associada às operações organizacionais instituídas no âmbito do arquivo corrente, há o termo arranjo, que aparece como sinônimo, no entanto é empregado para denominar as estruturações organizacionais de caráter permanente. (SIQUEIRA, 2009, p.56).

\section{AS RELAÇÕES ENTRE OS DOMÍNIOS DAS “TRÊS MARIAS”}

Observando as propostas de definição do termo classificação nos domínios das três Marias notamos que há grande proximidade terminológica, já que mesmo utilizando expressões linguísticas distintas reportam a significados análogos. Mesmo que a Arquivologia denomine as principais características do termo como "ação intelectual" e disposição físico-material"; a Biblioteconomia prefira as designações de "operação intelectual" e operação material"; e a Museologia opte por "aspecto intelectual" e "aspecto físico", temos nos três domínios uma representação comum, ou seja, o termo possui uma faceta de caráter cognitivo e outra de natureza material.

Quanto ao caráter cognitivo é comum nos três domínios o estabelecimento de classes que reúnam documentos com atributos comuns, ação que se diferencia entre as Marias no que tangem aos critérios para a sua elaboração. Assim, no âmbito da Arquivologia o elemento chave que definirá a organização sistemática é a função/atividade desempenhada pela entidade ou pessoa produtora do fundo, ou seja, é o caráter orgânico-funcional que delimita as classes. Já na Biblioteconomia as classes são definidas pelo assunto, também denominada como produto de representação temática. $\mathrm{Na}$ Museologia consideram-se os critérios da natureza da coleção, a função do objeto e a perspectiva do sujeito ou da civilização produtora do artefato.

O estabelecimento de classes permite estruturar os domínios como um sistema, operação enfrentada de modo distinto para cada Maria. $\mathrm{Na}$ Biblioteconomia, por exemplo, difundiram-se vários sistemas de classificação que perseguiram padrões universais de uma representação do conhecimento, caso da CDD e da CDU ou mesmo da Colon Classification, até aqueles voltados às particularidades de determinado acervo, como a LCC da Biblioteca do Congresso nos EUA. Já na Arquivologia considera-se para a estruturação do sistema de classificação o caráter da temporalidade do documento no arquivo. Na fase corrente, temos o Plano de Classificação, voltado à análise das funções e atividades do organismo produtor do arquivo; já na fase permanente temos o Quadro de Arranjo, responsável pela localização e recuperação de documentos não mais utilizados para fins administrativos e jurídicos, mas voltados à pesquisa histórica e a ação cultural. Quanto ao museu, por abranger coleções mais diversas e considerar distintos aspectos para a elaboração de classes, a representação sistemática é mais específica e voltada às necessidades de suas coleções. Além disso, diferentemente da tradição biblioteconômica e arquivística que já possuem sistemas estabelecidos, é comum observar uma readequação de tais sistemas para a utilização em museus. 
Em relação ao aspecto físico-material, também notamos uma proximidade funcional desse caráter nas três irmãs. Nos três domínios observamos que a classificação no âmbito material tem o objetivo de auxiliar na localização, acesso e recuperação de documentos, ações que se vinculam indiretamente à ação intelectual, pois a disposição física está atrelada à organização intelectual.

Vinculados à operação material, por seus caracteres pragmáticos, e à operação intelectual, por serem produzidos a partir da elaboração cognitiva das classes, os produtos da classificação também apresentam algumas proximidades e distinções entre as irmãs. O índice e o catálogo podem aparecer nos três domínios, no entanto, não só seu conteúdo, como sua estrutura pode ser totalmente distinta. O catálogo, por exemplo, considerado um instrumento de pesquisa pode ser elaborado segundo critérios temáticos, cronológicos, onomásticos ou geográficos. Mesmo se considerarmos um tipo, o temático, por exemplo, observamos que ele terá uma estrutura específica para cada instituição. No arquivo se consideram as séries arquivísticas, tendo como pressuposto o caráter da proveniência dos fundos; na biblioteca formada por uma coleção com obras múltiplas se evidenciará o assunto; já o museu com obras únicas, exige-se maior detalhamento de caracteres, o que justifica um catálogo raisoneé, por exemplo, usado na sobreposição de características temáticas com dados bibliográficos do artista.

$\mathrm{Na}$ tentativa de compreender as proximidades e distinções entre as "Três Marias" foi elaborada uma árvore domínio a fim de verificar as principais interrelações apontadas anteriormente, apresentada na Figura 1.

Figura 1 - Representação gráfica do termo classificação no domínio da Ciência da Informação

\section{Classificação pode ser entendida como}

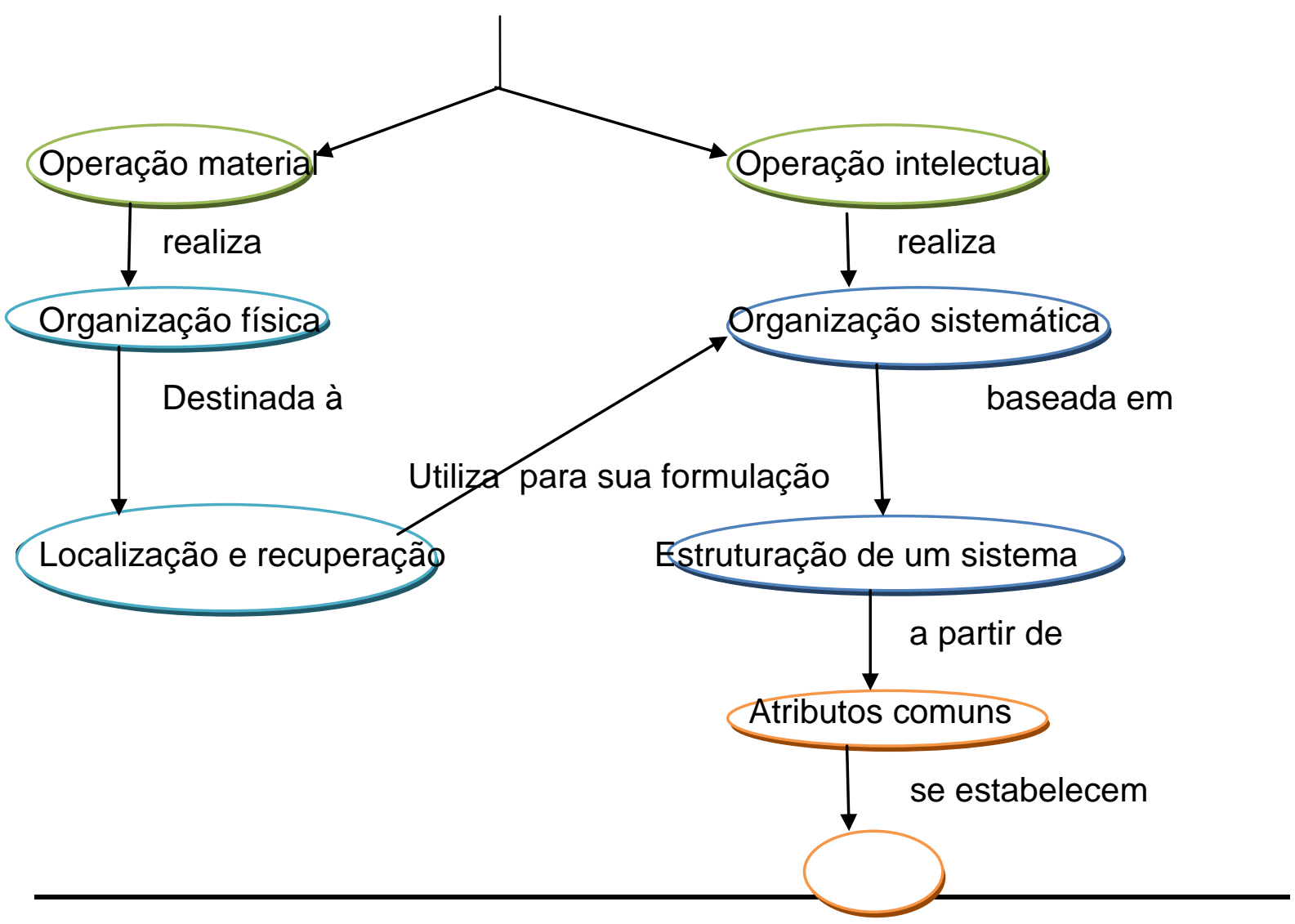




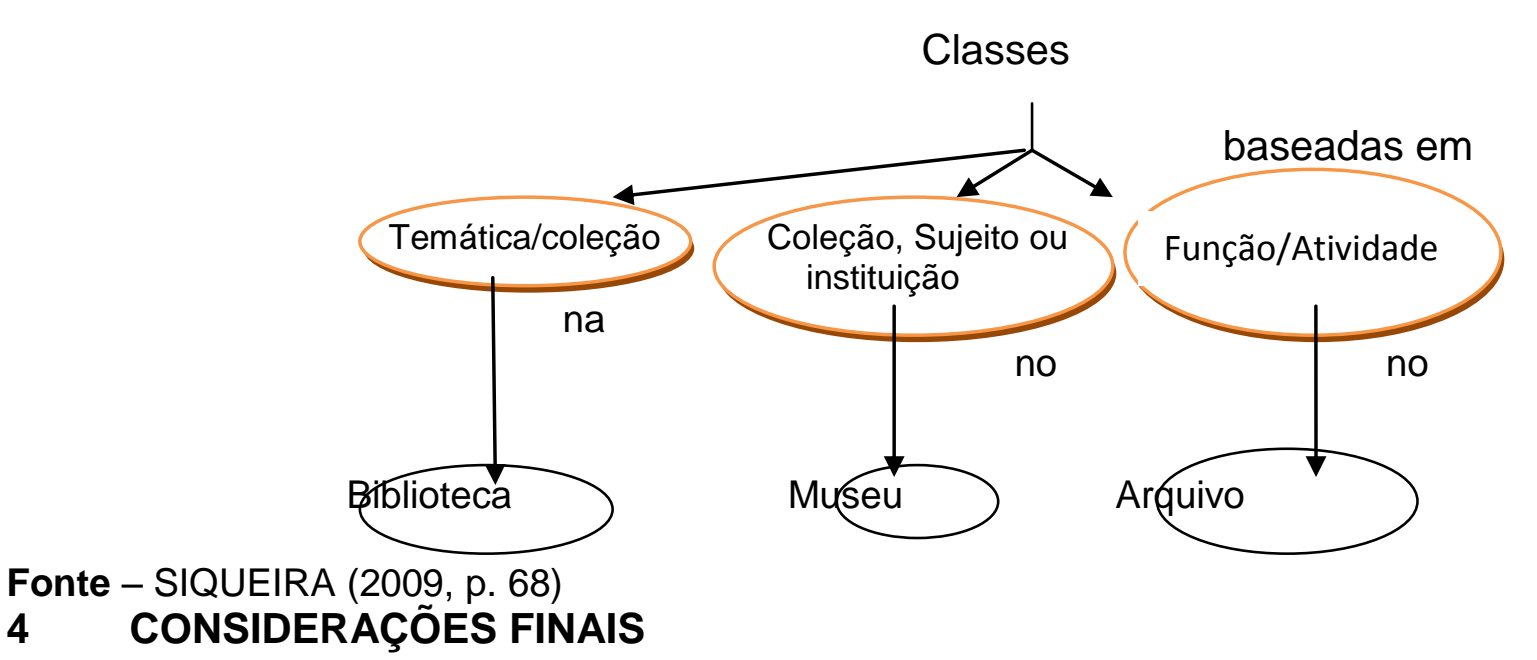

\begin{abstract}
A análise terminológica nos permitiu verificar, a partir do termo "classificação", como os domínios da Arquivologia, Biblioteconomia/Documentação e Museologia são próximos. No entanto, mesmo com origens e naturezas aproximadas se separaram no decurso da história, focalizando-se em suas técnicas e práticas e isolando-se em seu contexto. Tal isolamento acarretou uma visão tecnicista e extremamente vinculada ao paradigma do acervo, mais preocupado com a conservação e guarda dos documentos, que com sua utilização.
\end{abstract}

No entanto, influenciados pelas inovações tecnológicas a partir da segunda metade do século XX, e principalmente motivadas pelas mudanças sócio-culturais do contexto pós-moderno, observamos que hoje as três irmãs voltam-se a aproximar, ou pelo menos se mostram mais abertas ao diálogo e às inevitáveis trocas entre si. Assim, ao analisarmos um termo comum entre as três Marias - a classificação - foi possível identificar relações de contiguidade entre elas, uma vez que, apesar de suas particularidades, têm como objeto comum a informação. Outrora focalizadas no documento, evidenciando o caráter do suporte e do formato numa preocupação de guarda e conservação, hoje convergem seus enfoques à informação, voltadas a uma preocupação com o conteúdo e ao seu acesso pelos usuários.

Quanto ao termo classificação, podemos afirmar que as três Marias o definem como uma operação de duas naturezas: cognitiva e material, que mesmo denominadas por expressões sinônimas trazem em seu bojo uma operação intelectual e outra físico-material. Ainda que visualizadas separadamente, em atuações específicas - a sistematização de classes e a disposição física notamos que suas ações convergem e se inter-relacionam, pois no contexto dinâmico de cada domínio tais operações dialogam.

Outro aspecto que as aproxima no que tange à classificação é a adoção de uma estruturação sistemática, bem como a elaboração de classes para agrupar e separar os documentos por atributos comuns. No entanto, o que marca a distinção maior entre os domínios é o estabelecimento de classes que, para cada irmã, mobiliza um critério distinto: assunto (Biblioteconomia), natureza da coleção, perspectiva do sujeito, função do objeto (Museologia) e função/atividade da entidade produtora (Arquivologia). 
Ao término da análise, depois de verificar as proximidades e distinções do termo classificação nos domínios da Biblioteconomia/Documentação, Arquivologia e Museologia, percebeu-se que tal dialogismo entre as irmãs não se restringe à classificação, podendo-se ampliar a comparação para outros termos comuns a fim de se comprovar a manifesta inter-relação dos domínios.

\section{REFERÊNCIAS}

ARTÊNCIO, L. M. Princípios de categorização nas linguagens documentárias. 2007. 129 f. Dissertação (Mestrado em Ciência da Informação) - Universidade de São Paulo, São Paulo, 2007. Disponível em: <http://www.teses.usp.br/teses /disponiveis/27/27151/tde-30052008-152640/pt-br.php> Acesso em: 08 jul. 2009.

BARROS, L. A. Curso básico de terminologia. São Paulo: EDUSP, 2004.

BIANCHINIA. M. H.; FERREZ, H. D. Thesaurus para acervos museológicos. Rio de Janeiro: MINC; SPHAN, 1987.

CABRÉ, M. T. La terminologia - teoria, metodología, aplicaciones. Trad. Castelhana de Carles Tebé. Barcelona: Editorial Antártida/Empúries, 1993.

CERÁVOLO, S. M. Da palavra ao termo: um caminho para compreender a museologia. 2004. Tese (Doutorado em Biblioteconomia e Documentação) Escola de Comunicação e Artes, Universidade de São Paulo, São Paulo, 2004.

DUDLEY, D. et al. Museum registration methods. 3. ed. Washington: American Association of Museum, 1979.

DURKHEIM, Émile; MAUSS, Marcel. De quelques formes primitives de classification. [Algumas formas primitivas de classificação]. Contribuition a letude dês représentations collectives (1901) In: MAUSS, M. Ensaios de Sociologia. São Paulo: Perspectiva, 1981.

FONSECA, M. O. Arquivologia e Ciência da Informação. Rio de Janeiro: FGV, 2007.

FOUCAULT, M. As palavras e as coisas. São Paulo: Martins Fontes, 1996.

GONÇALVES, J. Como classificar e ordenar documentos de arquivo. São Paulo: Arquivo do Estado, 1998. (Projeto como fazer; v. 2). Disponível em:

<http://www.arquivoestado.sp.gov.br/saesp/texto_pdf_11_Como\%20Classificar\%2 0e\%20Ordenar\%20Documentos\%20de\%20Arquivo.pdf > Acesso em: 10 fev. 2009.

GROLIER, E. Classification as cultural artefacts. In: Universal Classification: subject, analisys and ordering systems. Procededing... INTERNATIONAL STUDY CONFERENCE ON CLASSICATION RESEARCH OF FID. $4^{\text {th }}$, v.2, p.19-34,1982. 
HOMULOS, P. Museums to libraries: a family of collecting insititutions. Art Libraries Journal, v. 15, n. 1, p. 11-13, 1990.

JOUGUELET, S. Classification. In: CACALY, Serge (Coord.). Dictionnaire encyclopédique de l'information et de la documentation. Paris: Nathan, 1997.

LARA, M. L. G. Elementos de terminologia. São Paulo: ECA-USP, 2005. (Apostila para uso didático).

MAROEVIC, I. Introduction of Museology: the european approach. Trad. Intertext Zagreb. Munich: Verlag. Dr. C. Müller-Straten, 1998.

OTLET, P. Tratado de documentación: el libro sobre el libro: teoría y práctica. Trad. de Hagar Espanha Gomes. Murcia: Universidad Murcia, 1996.

PERELMAN, C. Réflexions Philosophiques sur la Classification. In : CENTRE NATIONAL DE RECHERCHE DE LOGIQUE ; SOCIETE BELGE DE LOGIQUE ET PHILOSOPHIE DES SCIENCES. La Classification dans les Sciences. Bruxelles: Éditions J. Duculot, 1963.

PÉREZ-PULIDO, M.; MORILLAS, J. L. Teoría y nuevos escenarios de la Biblioteconomía. Buenos Aires: Alfagrama, 2005.

PIAGET, J. Aprendizagem Conhecimento. Rio de Janeiro: Freitas Bastos, 1979.

POMBO, O. Da classificação dos seres à classificação dos saberes. Leituras. Revista da Biblioteca Nacional de Lisboa, n. 2, p. 19-33, 1998. Disponível em:<http://www.educ.fc.ul.pt/hyper/resources/opombo-classificacao.pdf> Acesso em: 06 jul. 2009.

ROCHA, L. M. G. M. Museu, informação e comunicação: o processo de construção do discurso museográfico e suas estratégias. 1999. Dissertação (Mestrado em Ciencia da Informação) - Universidade Federal do Rio de Janeiro, Rio de Janeiro, 1999.

SAN SEGUNDO MANUEL, Rosa. Sistemas de organización del conocimiento: la organización del conocimiento en las bibliotecas españolas. Universidad Carlos III de Madrid; BOE: Madrid, 1996.

SIQUEIRA, J. C. A classificação nos domínios das três Marias: uma abordagem terminológica. 2009. Trabalho de Conclusão de Curso (Graduação em Biblioteconomia) - Escola de Comunicação e Artes, Universidade de São Paulo, São Paulo, 2009.

SMIT, J. W. Arquivologia, Biblioteconomia e Museologia: o que agrega estas atividades profissionais e o que as separa? Revista Brasileira de Biblioteconomia e Documentação. Nova Série, São Paulo, v. 1, n. 2, p. 27-36, 2000.

. O documento audiovisual ou a proximidade entre as 3 Marias. Revista Brasileira de Biblioteconomia e Documentação, São Paulo, v. 26, n. 1/2, p. 81-85, 1993. 


\title{
Title
}

Classification in the field of the "three Marys"

\begin{abstract}
A terminological analysis of the term "classification", in Archival Science, Library Science and Museum Studies shows that there are similarities and distinctions between these three domains of Information Science; the "three Marys". The study was based on a multilingual corpus of primary and secondary sources from the past twenty five years, and based on the analysis and synthesis cards technique, as suggested by Smit (1993). The proposed definitions show that the word "classification" has two meanings: one of a physical-material and other cognitive, being the latter responsible for structuring and for the systematic development of the classification schemes. Also, the organization of documents by common attributes is significant for the distinction between the domains, which apply peculiar criteria for establishing their classification schemes. Despite the peculiarity of each area, there is a clear contiguity between the "three Marys" which reveals an evident need for intensive dialogue and exchanges for a better articulation of those three Information Science dimensions in accordance to the contemporary context needs.
\end{abstract}

\section{Keywords}

Archival Science. Library Science. Museum Studies. Classification. Terminology.

\section{Titulo}

La clasificación en el dominio de las "tres Marias"

\section{Resumen}

El artículo destaca que un análisis terminológico de la expresión "clasificación", en Archivología, Biblioteconomía y Museología muestra que hay similitudes y diferencias entre los dominios. Observa las relaciones entre las "tres Marías" a partir de un corpus multilingüe, con un predominio de las publicaciones de los últimos 25 años, con textos de naturaleza primaria y secundaria, a partir de los ficheros del análisis y de síntesis, conforme sugiere Smit (1993). Destaca las propuestas de definiciones demostrando que el término "clasificación" tiene dos significados: uno de naturaleza físico-material y otro cognitiva, con destaque para la última responsable por la estructuración sistemática y la elaboración de las clases. Enfatiza que la separación de los documentos por atributos comunes, marca también la distinción entre los dominios, los cuales utilizan los criterios singulares para el establecimiento de clases. Por fin constata que mismo teniendo en cuenta las características específicas de cada dominio, hay una contigüidad clara entre las "tres Marías", lo que revela una necesidad cada vez más evidente de diálogo e intercambios para el establecimiento de un campo de estudio más articulado y centrado en las necesidades del contexto contemporáneo.

\section{Palabras clave}

Archivología - clasificación. Bibliotecología - clasificación. Museología - clasificación. Clasificación. Terminología. 
Recebido em: 05/02/2011

Aceito em: 08/06/2011 